\title{
The Genetic Basis of Primate Behavior: Genetics and Genomics in Field-Based Primatology
}

\author{
Lauren J. N. Brent • Amanda D. Melin
}

Received: 23 October 2013 /Accepted: 25 October 2013 /Published online: 29 November 2013

(C) Springer Science+Business Media New York 2013

Genetics is to biology what atomic theory is to physics.

- Steve Jones, Almost Like a Whale (1999, p. 142)

Recent advances in genetic and genomic techniques have led to explosive advances in the fields of biology and ecology. Perhaps nowhere is the stark difference between what was possible in genetics research 10 years ago compared to what can be done today as obvious as in field-based studies of animals. Whereas biologists of the past were severely limited by the costs of most genetic analyses, the biologists of today must cope with the time- and information-processing constraints associated with analyzing huge quantities of data - a privileged problem to be sure. This shift has been brought about most directly by the widespread use of massively parallel (or next-generation) sequencing, which has drastically reduced not only the costs of genotyping (a trend that continues), but also the quantity and quality of requisite DNA, as well as the amount of time required to complete genetics projects (Bradley and Lawler 2011; Perry 2014; Tung et al. 2010). These advances, in addition to the now commonplace presence of shared genomics infrastructure in research institutes and universities, have removed most of the major limitations to the use of genetic information by animal biologists.

Scholars that study nonhuman primates are particularly well poised to take advantage and benefit from this new wave of genetics. Interests in primates from the biomedical community, which stem from our shared taxonomic membership (McClure 1984; Rogers and Hixson 1997; Watson and Platt 2012), have resulted in the fullgenome sequencing of a relatively large number of primate species. The full-genome sequence has been published or is underway for at least 23 primate species (Bradley

L. J. N. Brent $(\bowtie)$

Duke Institute for Brain Sciences, Center for Cognitive Neuroscience, Duke University, Durham,

North Carolina 27708, USA

e-mail: lauren.brent@duke.edu

A. D. Melin (ه)

Department of Anthropology, Washington University, St. Louis, Missouri 63130, USA

e-mail: amelin@artsci.wustl.edu 
and Lawler 2011; Siepel 2009; Tung et al. 2010). Projects like the Genomes 10K Project, which aims to sequence approximately one genome for every genus of vertebrate (Genome 10K Community of Scientists 2009), will further advance this progress.

The study of behavior is one of the principle strengths of primatology. Primates live in a wide range of habitat types, have varied ecologies, and exhibit a broad array of social and sexual systems (Mitani et al. 2012). Biologists have dedicated many years to the study of primate behavior and have already uncovered a great deal about the evolutionary forces that shape these behaviors and social systems. These efforts have also resulted in a relatively large number of long-term primate field sites with behavioral and life-history data available for multiple generations of individuals (Fedigan 2013; Fedigan and Asquith 1991; Kappeler and Watts 2012). Yet, without the explicit use of genetic and genomic information, primatologists are restricted in their ability to answer some of the most fundamental questions in this field. Timely questions that would benefit from or explicitly require the use of genetic data include: How have primates acquired new and distinct ways of occupying divergent ecological niches? Why do primates occupy different phenotypic state spaces? How is behavioral variation between and within primate species generated and what are its consequences? What are the physiological and neurobiological mechanisms that underlie the production of behaviors in primates?

In this Special Issue of the International Journal of Primatology we highlight innovative research that integrates genetic and genomic data to better understand the behavior of wild or free-ranging primate populations. Articles found within this Special Issue include empirical research in a range of primate taxa, including apes, New and Old World monkeys, lemurs, and even computer-simulated "tamarins." These studies use newly emergent techniques for the collection and analysis of primate genetic and genomic data, from high-throughput gene sequencing to heritability analyses, and from computer simulation models to phylogenetic comparisons. This work, emphasizing field-based research, complements more established lines of research taking place on captive animals and in laboratory settings, e.g., using tissue cultures, where important topics, such as naturalistic foraging, dispersal, predation, survival, and longevity, cannot be examined. This Special Issue also contains a number of methods-based articles that offer detailed guidance to those hoping to incorporate genetic information into their research in the future. In this introduction to the Special Issue, we contextualize the content of these articles within the wider field of primatology to give readers a sense of the advancements to current knowledge that they represent. Important cautionary messages are found on repeated occasions throughout the issue, e.g., regarding sample sizes, and interpretative and methods-based pitfalls, and we also summarize these here. We conclude our introduction to this Special Issue with possible directions for the future study of the genetic basis of primate behavior.

\section{The Box is Becoming Less Black: Interplay Between Genes and Primate Behavior}

Genetics has historically been a black box in the study of primate behavior (Bradley and Lawler 2011). Yet, the diversity of subjects covered by this Special Issue attests to the breadth of primate behavioral research that now uses genetic data and demonstrates 
just how far we have come in recent years. The topics covered by these articles can be divided roughly into five categories, although there is certainly some overlap: visual ecology, phylogenetics, population genetics, social behavior, and genetics methods.

Visual adaptations distinguish primates from other mammals and are hypothesized to have played a key role in primate origins and adaptive radiation. It is, therefore, unsurprising that biologists have spent decades trying to understand the visual ecology of primates. Color vision in particular, which is highly variable both inter- and intraspecifically, has attracted intensive study (Jacobs 2010; Kawamura et al. 2012 for recent reviews) and is uniquely well suited for investigating the genetic basis of behavior. Unlike other sensory systems that are characterized by complex, polygenetic mechanisms, color vision phenotype is predictable in a straightforward manner from opsin gene sequences (Bradley and Lawler 2011; Deeb et al. 1992; Saito et al. 2005; Yokoyama 1997). Three articles in this Special Issue address the molecular ecology of primate color vision and are at the forefront of research in primate sensory ecology. First, Veilleux et al. (2014) unite molecular analyses of opsin genes with visual modeling analyses of food items to demonstrate that dichromatic color vision is under positive selection and adaptive for nocturnal foraging in the genus Avahi. Second, Melin et al. (2014) combine a genetic, ecological, and behavioral study of capuchins (Cebus capucinus) with a unique method of modeling food conspicuity to investigate the polymorphic color vision of New World monkeys. Finally, by sequencing the variable region of opsin genes and reconstituting visual pigments in vitro, Matsushita et al. (2014) reveal unanticipated variation in the color vision of howlers (Alouatta spp.) that calls into question the adaptive nature of routine trichromacy in this genus.

Although vision is vital for primates, other - previously neglected - senses also play important roles in foraging, reproduction, and other behaviors that are important to survival (Barton 2006; Dominy et al. 2004; Heymann 2006). Enhanced understanding of audition, somatosensation, olfaction, and gustation will generate new insights into primate adaptation and evolution. In particular, the chemical senses (smell and taste) are forecast to be hotspots of new research in primate sensory ecology. Primates are very sensitive to some chemicals that are important during foraging (Hernandez et al. 2003; Laska 2004). However, research into the detection and recognition of odorants and tastants has been hindered by the size and complexity of the gene families underlying chemosensation, e.g., olfactory receptor genes comprise one of the largest multigene families in mammals (Dong et al. 2009). Nevertheless, research investigating the selective pressures that operate on olfactory and taste receptor genes in humans, nonhuman primates, and other animals is on the rise (Alonso et al. 2008; Campbell et al. 2012; Gimelbrant et al. 2004; Go and Niimura 2008; Kishida et al. 2007; Lajoie et al. 2010; Matsui et al. 2010; Nei et al. 2008; Niimura and Nei 2005; Nozawa et al. 2007; Shykind 2005; Steiger et al. 2010; Sturm et al. 2013). This research is possible owing to recent advances in techniques for sequencing and analyzing molecular data, many of which are described in this Special Issue, e.g., Perry (2014). Our understanding of the nonvisual senses - including how these senses relate to one another - is in its infancy, but with the applications of recent genetic and genomic techniques to this field, the future of primate sensory ecology is bright.

Phylogenetics and population genetics are well established lines of research that have made significant contributions to our understanding of primate behavior (Di Fiore 2003; Opie et al. 2013; Shultz et al. 2011). The articles in this Special Issue build on 
this groundwork as well as making important advances. For example, Pozzi et al. (2014) argue that primatologists have a false sense of confidence in the current phylogenies presented in the literature and use modeling techniques to illustrate pitfalls that may be encountered (and should be avoided) when using phylogenetic data. Owing to the pervasiveness and importance of phylogenetic research, Pozzi et al. (2014) have produced a significant contribution to the debate regarding the level of resolution of the current primate phylogeny about which most, if not all, primatologists should be aware. Genetic techniques can also be used to characterize social systems of primate species that are currently poorly understood. Koop et al. (2014) use an impressive set of genetic diversity data to demonstrate that, unlike almost all other baboon species (Papio spp.), wild guinea baboons (P. papio) exhibit female dispersal. Taking a different approach, Di Fiore and Valencia (2014) apply a spatially explicit agentbased population genetics model to explore the potential effects of social and landscape features on the genetic structure of simulated tamarin groups. This type of modeling allows primatologists to generate new hypotheses and provides greater insight into factors influencing population genetic structure, and the dispersal patterns from which this structure emerges, than is possible using field-based data alone.

The genetic basis of behaviors that are specifically social in nature occupies much of this issue. Understanding the extent to which affiliative social interactions between females are kin biased is crucial to our understanding of both primate social systems as well as the mechanisms underlying the evolution of cooperation (Brent et al., in press). Although these questions have been tackled in some of the more extensively studied primates, e.g., genera Macaca and Papio, much less is known in other taxa. However, new empirical research has begun to fill in these gaps. Tinsley Johnson et al. (2014) use genetic data to confirm previous reports that closely related female geladas, Theropithecus gelada, interact in an affiliative manner more frequently than do unrelated females. Montague et al. (2014) provide a compelling example of the insight that can be achieved by integrating genetic, social, and foraging data. These authors examine whether affiliative associations among wild squirrel monkeys (Saimiri sciureus macrodon) are kin biased, and assess whether these relationships influence the success of females at capturing insects.

Although it should be no more controversial than studying say, a morphological trait, attempts to identify specific genes that underlie the production of social behavior have been met with some derision from the public, as well as from the scientific community at large (Ridley 2003). In addition to navigating this somewhat negative atmosphere, studies of the genetics of social behavior must also overcome the theoretical and methodological hurdles associated with the pleiotropic nature of social behaviors. Crucial groundwork for this type of research requires careful descriptions of the variation that exists in genes that are of potential functional relevance. In this issue, Babb et al. (2014) and Anestis et al. (2014) document variation in genes in two key neuromodulatory pathways. Babb et al. (2014) explore variation in the prolactin receptor gene within and between several primate taxa, while Anestis et al. (2014) compare genetic variation in the vasopressin pathway between wild and captive populations of chimpanzees (Pan troglodytes). The study by Anestis et al. (2014) also explores whether genetic variation is predictive of personality markers in their 
study subjects, and represents a prime example of the types of inferences that can be drawn when results from captive and wild populations are combined.

Finally, the Special Issue contains a number of methods-based primers that reflect the scientific innovations of the authors and provide a crucial service to the discipline. Quantitative genetic models allow primatologists to explore the heritability of behavioral traits, as well as genetic correlations between traits. Adams (2014), and Blomquist and Brent (2014) give step-by-step guides to the application of such models. Major Histocompatibility Complex (MHC) genes have implications for our understanding of not only immune systems, but also socially relevant topics such as individual recognition and mate choice. Huchard and Pechouskova (2014) provide a thorough overview of the most up-to-date methods used to explore MHC genes and carefully outline the major pitfalls primatologists should try to avoid. Studies conducted at the scale of entire genomes have enormous, and largely untapped, potential to advance our understanding of the natural history of organisms and inform conservation decisions. Perry (2014) provides a user-friendly tour of the technology and methods involved in genomic-scale studies of primate populations, with emphasis on applications for endangered or rare species. Together, these reviews will guide future studies of primate behavioral genetics and provide the groundwork for important empirical findings and advancements.

\section{Messages to Take Away from the Special Issue}

Here, we summarize some of the most important concerns and recommendations, especially those pertaining to methodological practices, which are highlighted in this Special Issue. Sample size is discussed on many occasions (Adams 2014; Blomquist and Brent 2014; Brent et al. 2014; Huchard and Pechouskova 2014) and should not go unnoticed. This is especially relevant for studies that use quantitative genetic analysis, as well as to those that examine functional genetics. The recommended sample size of 100 or more individuals may be prohibitively large for many primatologists, especially those studying solitary or critically endangered species, but should not be an outright deterrent. There are many questions that can be addressed using sample sizes that are more typical in studies of primate behavior and smaller studies can provide valuable pilot data that can be used to shape future research and encourage funding.

The importance of knowing the extent to which study subjects are related is another common thread found throughout much of the issue. Information on maternal relatedness can often be ascertained without genetic data as many primate species express maternal care toward their offspring, e.g., lactation, carrying. In contrast, genetic data are usually required in order to establish relatedness along paternal lines because behavioral markers of paternity do not exist for the majority of primate species. Without relatedness data, primatologists are unable to determine the impact of kinship on the patterning of social interactions, which is important in studies of kin bias (Berman and Kapsalis 1999; Seyfarth 1977), kin recognition (Widdig et al. 2001), and inbreeding avoidance (Hammond et al. 2006). Heritability analyses also require that relatedness between subjects is known, with the ability to estimate heritability reliably increasing 
with the depth and resolution of the pedigree used (Wilson et al. 2010). Relatedness between individuals is also necessary to calculate some measures of reproductive output, such as number of offspring sired, which can then be used to examine the reproductive consequences of traits (Brent et al. 2013; Gilby et al. 2013).

Specific questions aside, the presence of closely related individuals in a dataset has important implications for all studies of primate behavior - not just those with questions specific to genetics. As explained in detail in the Special Issue, closely related individuals are more likely to possess similar phenotypes not only because they have similar experiences and live in similar environments, but also because they possess similar genotypes (Adams 2014; Blomquist and Brent 2014). Statistical analyses that include data from closely related subjects therefore violate the assumption of independent data points. Controlling for relatedness between subjects is not difficult in modern regression models (Wilson et al. 2010) and should perhaps become more common practice in studies of primate behavior for which data on closely related individuals are highly pervasive. Brent et al. (2014) control for intersubject relatedness when examining the relationship between personality and reproductive output in female rhesus macaques (Macaca mulatta), but this might be the first example of a study of primate behavior to do so. Further research is required to determine the extent to which the inclusion of related subjects impacts on the results of primate behavioral research. In sum, there are a great many reasons for primatologists to obtain extensive pedigree data on their study subjects. Indeed, we encourage researchers to begin collecting fecal samples for genetic analysis, even if they do not have immediate plans to use them. Fecal samples are easily and inexpensively stored, and the DNA that can be obtained from them represents a major investment in future research.

The Special Issue also draws attention to some of the best taxa and field sites at which to conduct genetics and genomics-based primatological research. With well documented color vision polymorphisms, New World monkeys and lemurs will continue to be excellent study subjects for visual ecologists. Comparisons of the foraging strategies and molecular ecologies of strepsirrhine, platyrrhine, and catarrhine primates will also be an exciting area for the study of the genetic bases of olfactory and other sensory behaviors. Many long-term field sites have extensive databanks of behavioral observations on tens if not hundreds of animals with extended pedigrees either in place or under development. These sites will act as clear starting points for primate researchers interested in performing quantitative genetic analyses and in exploring the functional genetic basis of behavioral traits. Other, newer, field sites are in prime position to organize their data collection in a manner that is optimally designed for future genetic work in mind. This includes any site at which data can be collected on large number of individuals and at which DNA samples can be obtained (noting that noninvasive techniques are continually being improved: Perry et al. 2010; Surridge et al. 2002). The Special Issue also draws attention to the taxonomic gaps that exist in studies of primate behavioral genetics. Very few genetic or genomic projects involving colobines, guenons, or species of New World monkey have been produced. Lemurs are also underrepresented, although a recent push to sequence the genomes of many lemurs (Bradley and Lawler 2011) will hopefully results in rapid improvements in this area. 


\section{Conclusions}

Recent advances in genetics and genomics have brought about a new dawn of biological enquiry. No longer a black box, we can now directly examine the building blocks of life that eluded Darwin, and from which the bodies and behaviors of all animals have ultimately emerged. Our formidable understanding of the behaviors of primates, the benefit of years of careful and intensive study, will allow primatologists to deftly leverage genetic and genomic data to detect the effects of natural selection and to build realistic models of the dynamic contigency that exists among genes, behaviors, the environment, and fitness (Chang et al. 2013). This is one of the greatest challenges the field of primatology has faced to date and one that we hope will continue to be embraced with as much zeal as has been demonstrated by the contributors to this Special Issue.

Acknowledgments We would first like to thank the participants of the symposium entitled "Inside the Black Box: The Genetic Basis of Primate Behavior" that took place at the XXIV Congress of the International Primatological Society in Cancun, Mexico and that led to this Special Issue, along with Noah Snyder-Mackler for co-organizing the symposium. We extend great thanks to Jo Setchell and James Higham for inviting us to guest edit this Special Issue and for their support throughout the process. We thank also Dennis Galvanez and Terry Kornak at Springer for editorial support. The individuals who contributed to this Special Issue made our lives as editors easy by submitting excellent work. We thank each of them for their collegiality and for helping us to create an issue of International Journal of Primatology of which we should all be proud. Finally, we thank Michael Platt and Nathaniel Dominy for their mentorship during the creation of this issue. L. J. N. Brent was supported by NIH grants R01-MH089484 and R01-MH096875 and by a fellowship from the Duke Center for Interdisciplinary Decision Sciences. A. D. Melin was supported by a fellowship from the Natural Sciences and Engineering Research Council of Canada (NSERC).

\section{References}

Adams, M. (2014). Feasibility and uncertainty in behavior genetics for the nonhuman primate. International Journal of Primatology. doi:10.1007/s10764-013-9722-8. (this issue)

Alonso, S., Lopez, S., Izagirre, N., \& de la Rua, C. (2008). Overdominance in the human genome and olfactory receptor activity. Molecular Biology and Evolution, 25, 997-1001.

Anestis, S. F., Webster, T. H., Kamilar, J. S., Fontenot, B., Watts, D. P., \& Bradley, B. J. (2014). AVPR1A variation in chimpanzees (Pan troglodytes): Population differences and association with behavioral style. International Journal of Primatology (this issue).

Babb, P., McIntosh, A., Fernandez-Duque, E., \& Schurr, T. (2014). Prolactin receptor gene diversity in Azara's owl monkeys (Aotus azarai) and humans (Homo sapiens) suggests a non-neutral evolutionary history among primates. International Journal of Primatology. doi:10.1007/s10764-013-9721-9 (this issue).

Barton, R. A. (2006). Olfactory evolution and behavioral ecology in primates. American Journal of Primatology, 68, 545-558.

Berman, C. M., \& Kapsalis, E. (1999). Development of kin bias among rhesus monkeys: Maternal transmission or individual learning? Animal Behaviour, 58, 883-894.

Blomquist, G., \& Brent, L. N. (2014). Applying quantitative genetic methods to primate social behavior. International Journal of Primatology. doi:10.1007/s10764-013-9709-5 (this issue).

Bradley, B. J., \& Lawler, R. R. (2011). Linking genotypes, phenotypes, and fitness in wild primate populations. Evolutionary Anthropology, 20, 104-119.

Brent, L. J. N., Chang, S. W., Gariepy, J. F., Platt, M. L. (in press). The neuroethology of friendship. Annals of the New York Academy of Sciences, The Year in Cognitive Neuroscience.

Brent, L. J. N., Heilbronner, S. R., Horvath, J. E., Gonzalez-Martinez, J., Ruiz-Lambides, A., Robinson, A. G., Skene, J. H. P., \& Platt, M. L. (2013). Genetic origins of social networks in rhesus macaques. Scientific Reports. doi:10.1038/srep01042. 
Brent, L. J. N., Semple, S., MacLarnon, A., Gonzalez-Martinez, J., Ruiz-Lambides, A., \& Platt, M. L. (2014). Personality traits in rhesus macaques are heritable but do not predict reproductive output. International Journal of Primatology. doi:10.1007/s10764-013-9724-6 (this issue).

Campbell, M. C., Ranciaro, A., Froment, A., Hirbo, J., Omar, S., Bodo, J. M., Nyambo, T., Lema, G., Zinshteyn, D., Drayna, D., Breslin, P. A., \& Tishkoff, S. A. (2012). Evolution of functionally diverse alleles associated with PTC bitter taste sensitivity in Africa. Molecular Biology and Evolution, 29, 11411153.

Chang, S. W. C., Brent, L. J. N., Adams, G. K., Klein, J. T., Pearson, J. M., Watson, K. K., \& Platt, M. L. (2013). Neuroethology of primate social behavior. Proceedings of the National Academy of Sciences of the United States of America. doi:10.1073/pnas.1301213110.

Deeb, S., Lindsey, D., Hibiya, Y., Sanocki, E., Winderickx, J., Teller, D., \& Motulsky, A. (1992). Genotypephenotype relationships in human red/green color-vision defects: molecular and psychophysical studies. American Journal of Human Genetics, 51, 687-700.

Di Fiore, A. (2003). Molecular genetic approaches to the study of primate behavior, social organization, and reproduction. American Journal of Physical Anthropology, 37, 62-99.

Di Fiore, A., \& Valencia, L. M. (2014). The interplay of landscape features and social system on the genetic structure of a primate population: An agent-based simulation study using "tamarin" monkeys. International Journal of Primatology. doi:10.1007/s10764-013-9726-4 (this issue).

Dominy, N., Ross, C., \& Smith, T. (2004). Evolution of the special senses in primates: Past, Present and Future. Anatomical Record, 281A, 1078-1082.

Dong, D., He, G., Zhang, S., \& Zhang, Z. (2009). Evolution of olfactory receptor genes in primates dominated by birth-and-death process. Genome Biology and Evolution, 1, 258-264.

Fedigan, L. (2013). Questions my mother asked me: An inside view of a thirty-year primate project in Costa Rica. In K. B. Strier (Ed.), Primate ethnographies. Upper Saddle River, NJ: Pearson/Prentice Hall.

Fedigan, L., \& Asquith, P. (Eds.). (1991). The Monkeys of Arashiyama: 35 years of research in Japan and in the west. Albany: State University of New York Press.

Genome 10KCommunity of Scientists. (2009). Genome 10K: A proposal to obtain whole-genome sequence for 10000 vertebrate species. Journal of Heredity, 100, 659-674.

Gilby, I. C., Brent, L. J. N., Wroblewski, E. E., Rudicell, R. S., Hahn, B. H., Goodall, J., \& Pusey, A. E. (2013). Fitness benefits of coalitionary aggression in male chimpanzees. Behavioral Ecology and Sociobiology, 67, 373-381.

Gimelbrant, A. A., Skaletsky, H., \& Chess, A. (2004). Selective pressures on the olfactory receptor repertoire since the human-chimpanzee divergence. Proceedings of the National Academy of Sciences of the United States of America, 101, 9019-9022.

Go, Y., \& Niimura, Y. (2008). Similar numbers but different repertoires of olfactory receptor genes in humans and chimpanzees. Molecular Biology and Evolution, 25, 1897-1907.

Hammond, R. L., Handley, L. J., Winney, B. J., Bruford, M. W., \& Perrin, N. (2006). Genetic evidence for female-biased dispersal and gene flow in a polygynous primate. Proceedings of the Royal Society of London B: Biological Sciences, 273, 479-484.

Hernandez, S., Laska, M., \& Rodriguez, L. (2003). Olfactory sensitivity for aliphatic esters in spider monkeys (Ateles geoffroyi). Behavioral Neuroscience, 117, 1142-1149.

Heymann, E. W. (2006). The neglected sense-olfaction in primate behavior, ecology, and evolution. American Journal of Primatology, 68, 519-524.

Huchard, E., \& Pechouskova, E. (2014). The major histocompatibility complex and primate behavioral ecology: New tools and future questions. International Journal of Primatology. doi:10.1007/s10764013-9700-1 (this issue).

Jacobs, G. H. (2010). The Verriest Lecture 2009: Recent progress in understanding mammalian color vision. Ophthalmic and Physiological Optics, 30, 422-434.

Jones, S. (1999). Almost like a whale: The origin of species updated. London: Doubleday.

Kappeler, P. M., \& Watts, D. P. (2012). Long-term field studies of primates. Berlin: Springer-Verlag.

Kawamura, S., Hiramatsu, C., Melin, A. D., Schaffner, C. M., Aureli, F., \& Fedigan, L. M. (2012). Polymorphic color vision in primates: Evolutionary considerations. In H. Hirai, H. Imai, \& Y. Go (Eds.), Post genome biology of primates (pp. 93-120). Tokyo: Springer Science+Business Media.

Kishida, T., Kubota, S., Shirayama, Y., \& Fukami, H. (2007). The olfactory receptor gene repertoires in secondary-adapted marine vertebrates: Evidence for reduction of the functional proportions in cetaceans. Biology Letters, 3, 428-430.

Koop, G. H., Ferreira da Silva, M. J., Fischer, J., Brito, J. C., Regnaut, S., Roos, C., \& Zinner, D. (2014). Patterns of mitochondrial DNA variation in baboons: The influence of social systems. International Journal of Primatology. doi:10.1007/s10764-013-9725-5 (this issue). 
Lajoie, M., Bertrand, D., \& El-Mabrouk, N. (2010). Inferring the evolutionary history of gene clusters from phylogenetic and gene order data. Molecular Biology and Evolution, 27, 761-772.

Laska, M. (2004). Olfactory sensitivity for carboxylic acids in spider monkeys and pigtail macaques. Chemical Senses, 29, 101-109.

Matsui, A., Go, Y., \& Niimura, Y. (2010). Degeneration of olfactory receptor gene repertories in primates: No direct link to full trichromatic vision. Molecular Biology and Evolution, 27, 1192-1200.

Matsushita, Y., Oota, H., Welker, B. J., Pavelka, M. S., \& Kawamura, S. (2014). Color vision variation as evidenced by hybrid L/M opsin genes in wild populations of trichromatic Alouatta New World monkeys. International Journal of Primatology. doi:10.1007/s10764-013-9705-9 (this issue).

McClure, H. M. (1984). Nonhuman primate models for human disease. Advances in Veterinary Science and Comparative Medicine, 28, 267-304.

Melin, A. D., Hiramatsu, C., Parr, N., Matsushita, Y., Kawamura, S., \& Fedigan, L. M. (2014). The behavioural ecology of color vision: Considering fruit conspicuity, detection distance and dietary importance. International Journal of Primatology. doi:10.1007/s10764-013-9730-8 (this issue)

Mitani, J. C., Call, J., Kappeler, P. M., Palombit, R. A., \& Silk, J. B. (2012). The evolution of primate societies. Chicago: University of Chicago Press.

Montague, M. J., Disotell, T. R., \& Di Fiore, A. (2014). Population genetics, dispersal and kinship among wild squirrel monkeys: Preferential association among closely-related females and its implications for insect prey capture success. International Journal of Primatology. doi:10.1007/s10764-013-9723-7 (this issue).

Nei, M., Niimura, Y., \& Nozawa, M. (2008). The evolution of animal chemosensory receptor gene repertoires: Roles of chance and necessity. Nature Reviews Genetics, 9, 951-963.

Niimura, Y., \& Nei, M. (2005). Evolutionary dynamics of olfactory receptor genes in fishes and tetrapods. Proceedings of the National Academy of Sciences of the United States of America, 102, 6039-6044.

Nozawa, M., Kawahara, Y., \& Nei, M. (2007). Genomic drift and copy number variation of sensory receptor genes in humans. Proceedings of the National Academy of Sciences of the United States of America, 104, 20421-20426.

Opie, C., Atkinson, Q. D., Dunbar, R. I. M., \& Shultz, S. (2013). Male infanticide leads to social monogamy in primates. Proceedings of the National Academy of Sciences of the United States of America, 110, 1332813332.

Perry, G. (2014). The promise and practicality of population genomics research with endangered species. International Journal of Primatology. doi:10.1007/s10764-013-9702-z (this issue).

Perry, G. H., Marioni, J. C., Melsted, P., \& Gilad, Y. (2010). Genomic-scale capture and sequencing of endogenous DNA from feces. Molecular Ecology, 19, 5332-5344.

Pozzi, L., Bergey, C., \& Burrell, A. (2014). The use (and misuse) of phylogenetic trees in comparative behavioral analyses. International Journal of Primatology. doi:10.1007/s10764-013-9701-0 (this issue).

Ridley, M. (2003). Nature via nurture: Genes, experience and what makes us human. New York: Harper Collins.

Rogers, J., \& Hixson, J. E. (1997). Baboons as an animal model for genetic studies of common human disease. American Journal of Human Genetics, 61, 489-493.

Saito, A., Kawamura, S., Mikami, A., Ueno, Y., Hiramatsu, C., Koida, K., Fujita, K., Kuroshima, H., \& Hasegawa, T. (2005). Demonstration of a genotype-phenotype correlation in the polymorphic color vision of a non-callitrichine New World monkey, capuchin (Cebus apella). American Journal of Primatology, $67,471-485$.

Seyfarth, R. M. (1977). A model of social grooming among adult female monkeys. Journal of Theoretical Biology, 65, 671-698.

Shultz, S., Opie, C., \& Atkinson, Q. D. (2011). Stepwise evolution of stable sociality in primates. Nature, 479, 219-222.

Shykind, B. M. (2005). Regulation of odorant receptors: One allele at a time. Human Molecular Genetics, 14, R33-R39.

Siepel, A. (2009). Phylogenomics of primates and their ancestral populations. Genome Research, 19, 19291941.

Steiger, S. S., Fidler, A. E., Mueller, J. C., \& Kempenaers, B. (2010). Evidence for adaptive evolution of olfactory receptor genes in 9 bird species. The Journal of Heredity, 101, 325-333.

Sturm, T., Leinders-Zufall, T., Macek, B., Walzer, M., Jung, S., Pommerl, B., Stevanovic, S., Zufall, F., Overath, P., \& Rammensee, H. G. (2013). Mouse urinary peptides provide a molecular basis for genotype discrimination by nasal sensory neurons. Nature Communications, 4, 1616.

Surridge, A. K., Smith, A. C., Buchanan-Smith, H. M., \& Mundy, N. I. (2002). Single-copy nuclear DNA sequences obtained from noninvasively collected primate feces. American Journal of Primatology, 56, $185-190$. 
Tinsley Johnson, E., Snyder-Mackler, N., Beehner, J. C., \& Bergman, T. J. (2014). Kinship and dominance rank influence the strength of social bonds in female geladas. International Journal of Primatology. doi: 10.1007/s10764-013-9733-5 (this issue).

Tung, J., Alberts, S. C., \& Wray, G. A. (2010). Evolutionary genetics in wild primates: Combining genetic approaches with field studies of natural populations. Trends in Genetics, 26, 353-362.

Veilleux, C. C., Jacobs, R. L., Cummings, M. E., Louis, E. E., \& Bolnick, D. A. (2014). Opsin genes and visual ecology in a nocturnal folivorous lemur. International Journal of Primatology. doi:10.1007/ s10764-013-9708-6 (this issue).

Watson, K. K., \& Platt, M. L. (2012). Of mice and monkeys: Using non-human primate models to bridge mouse- and human-based investigations of autism spectrum disorders. Journal of Neurodevelopmental Disorders, 4, 21.

Widdig, A., Nürnberg, P., Krawczak, M., Streich, W. J., \& Bercovitch, F. B. (2001). Paternal relatedness and age proximity regulate social relationships among adult female rhesus macaques. Proceedings of the National Academy of Sciences of the United States of America, 98, 13769-13773.

Wilson, A., Reale, D., Clements, M., Morrissey, M., Postma, E., Walling, C. A., Kruuk, L. E. B., \& Nussey, D. H. (2010). An ecologist's guide to the animal model. Journal of Animal Ecology, 79, 13-26.

Yokoyama, S. (1997). Molecular genetic basis of adaptive selection: Examples from color vision in vertebrates. Annual Review of Genetics, 31, 315-336. 